\title{
http://bjas.journals.ekb.eg \\ Application of Pediatric Index of Mortality 2 as a Scoring System in Predicting Outcome in Pediatric Intensive Care Unit in Banha Children Hospital
}

H.A.Elghaiaty, R.S.Arafa, E.H.Assor and H.A.El Nawawy

Pediatrics Dept., Faculty of Medicine, Benha Univ., Benha, Egypt

E-Mail:Heba2356@gmail.com

\begin{abstract}
Mortality prediction models are useful in Pediatric Intensive Care Unit (PICU) settings as risk assessment tools. Pediatric list of mortal sin PIM2 score is as a rule connected toward the duration of the time about confirmation will escalated consideration care, Dissimilar to different prognostic scores which might be ascertained during duration of the time intervals for those patient's remain On emergency unit. The point about this fill in might have been will assess the convenience from claiming PIM2 score in foreseeing mortal sin. This might have been An prospective perception investigation which carried out at PICU of Banha Youngsters doctor's facility with respect to 50 patients tolerant were undergone PIM 2 scoring Throughout their confirmation inside the Initially hour following confirmation. The result might have been recorded Likewise demise or release. The proportion from claiming watched should predicted mortal sin proportion standard mortal sin proportion (SMR) might have been ascertained for those set for tolerant. In regards to result of the examine number demise rate might have been (36\%). PIM2 score were fundamentally higher "around passing over released cases. Measurable noteworthy certain correspondence the middle of PIM2 score and (risk of mortal sin and span for remain. The display contemplate exhibits and also blacks a great capability of PIM2 will separate survivors from non-survivors. Those real mortality might have been $36 \%$ and the predicted mortality Eventually Tom's perusing PIM 2 score might have been half, Along these lines those institutionalized mortal sin proportion might have been 0.72 signifying overestimation about mortality or useful execution of our unit. A great biased capability of PIM2 on separate survivors from non-survivors. PIM2 show great alignment ( $p>0.05$ to nonsurvivors Furthermore On survivors).
\end{abstract}

Keywords: Mortality, PICU, PIM2.

\section{Introduction}

Mortality for patients admitted with pediatric emergency unit Units (PICUs) will be a generally re cognized Conclusion pointer Also might have been accounted for to shift from $3.8 \%$ on $13 \%$ overall [1].

A few scoring models that anticipate the danger of mortal sin about pediatric patients admitted of the emergency unit are accessible [2]. Mortal sin prediction models would advantageous in PICU settings as hazard appraisal instruments Also as An benchmark for the caliber of forethought the middle of offices [3].

Prediction instruments must separate great between survivors and non-survivors and be well adjusted preceding they might be connected usefully should assess alternately institutionalize correlations about PICUs or should right for case-mix contrasts the middle of bunches clinched alongside observational investigations [4]. Pediatric list for mortal sin (PIM) might have been initial formed done 1997 Also Concerning illustration the vast majority other prognostic scoring systems, might have been upgraded on PIM 2 which might have been watched to have better unoriginality of the result for pediatric patients admitted should emergency unit. PIM2 score is generally connected during those the long haul for confirmation with escalated consideration care, Dissimilar to different prognostic scores which might a chance to be ascertained at duration of the time intervals for the patient's remain in emergency unit [5]. A few investigations bring archived PIM2 Concerning illustration a suitableness danger evaluation apparatus to prediction of mortal sin Around pediatric patients, constantly the The majority exact Around a few models, and Hosting the best fit in diverse symptomatic and danger Assemblies [6]. It will be recent, uninhibitedly accessible same time a significant number other rating instruments require An permit Also over addition, PIM2 need An little amount of variables, Therefore it may be effectively computed [2]. Those point for this fill in might have been will assess the convenience for pediatric list for Mortality2 ( PIM2) score done foreseeing mortal sin done Banha Youngsters healing center seriousness.

\section{Subjects and methods \\ 2.1 Patients \\ Study design}

This was a prospective observation study which done at Pediatric intensive Care Unit (PICU ) of Banha children hospital on 50 patients age more than 1 month and less than $16 \mathrm{y}$, who were admitted to Banha children hospital during a 6 month period need intensive care services. Patient were undergone PIM 2 scoring during their admission within the first hour after admission.The outcome was recorded as death or discharge .

\section{Inclusion criteria}

All children admitted to Pediatric intensive care unit of Banha children hospital ICU from age of 1 month to age of $16 y$, due to surgical or medical problem.

\section{Exclusion criteria}

1. Patient below age of 1 month or above $16 \mathrm{y}$.

2. Patient transferred to another PICU outside the hospital.

3. Death in less than $2 \mathrm{~h}$ After PICU admission or 
discharged within $24 \mathrm{~h}$ after admission.

\subsection{Methods}

Children included in this study were subjected to:

1. Detailed history taking.

2. Full clinical examination on admission.

3. Collecting and re cording all data of the patient inquiring in the study including age, sex, type of admission ( elective or emergent ), referring specialty, diagnosis, failing organ system and duration of ICU stay.

4. Pediatric Index of Mortality 2 were scored within an hour of admission to pediatric intensive care unit using a structured data collecting from.

5 . The ratio of observed to predicted mortality ratio (standard mortality ratio ( SMR) ) was calculated for the set of patient.

Table (I) PTM 2 score[7].

\begin{tabular}{|c|c|c|c|}
\hline \multirow[t]{2}{*}{ Variables } & \multicolumn{2}{|c|}{ Values } & \multirow[t]{2}{*}{ Beta } \\
\hline & 1 & $\mathbf{0}$ & \\
\hline Elective admission & Yes & No & \\
\hline Recovery from surgery & Yes & No & \\
\hline Admitted following cardiac bypass or catheterization & Yes & No & \\
\hline Response of the pupils to bright light & \multicolumn{2}{|c|}{ fixed } & \\
\hline Mechanical ventilation (at first hour in ICU) & Yes & No & \\
\hline Systolic Blood Pressure & $(\ldots \ldots \ldots) \mathrm{mmHg}$ & Unknown $=120 \mathrm{mmHg}$ & \\
\hline Bass excess (arterial or capillary blood) & $(\ldots \ldots \ldots) \mathrm{mmol}$ & Unknown & \\
\hline $\mathrm{FiO}_{2}(\%) / \mathrm{PaO}_{2}(\mathrm{mmHg})$ & $\begin{array}{l}(\ldots . . \%) / \\
(\ldots . m m H\end{array}$ & Unknown & \\
\hline High risk diagnosis (Record number in brackets. If & 0 & None & \\
\hline \multirow[t]{9}{*}{ doubt record 0) } & 1 & rdiac arrest out of hospital & \\
\hline & Sever & nbined immune deficiency & \\
\hline & Leukem & lymphoma after induction & \\
\hline & Spor & neous cerebral hemorrhage & \\
\hline & 5 & omyopathy or myocarditis & \\
\hline & 6 & plastic left heart syndrome & \\
\hline & 7 & HIV infection & \\
\hline & 8 & $\begin{array}{l}r \text { failure if main reason for } \\
\text { admission }\end{array}$ & \\
\hline & 9 & Teurodegenerative disorder & \\
\hline Low risk diagnosis (Record number in brackets. If & 0 & None & \\
\hline \multirow[t]{5}{*}{ doubt record 0) } & Asthma & main reason for admission & \\
\hline & 2 & $\begin{array}{l}\text { chiolitis is main reason for } \\
\text { admission }\end{array}$ & \\
\hline & Croup & main reason for admission & \\
\hline & Obstructi & $\begin{array}{l}\text { sleep apnea is main reason } \\
\text { for admission }\end{array}$ & \\
\hline & DKA & main reason for admission & \\
\hline $\begin{array}{l}\text { DKA: Diabetic Keto Acidosis FiO2: Fraction of inspire } \\
\text { HIV: Human Immunodeficiency Virus } \\
\text { PaO2: Pressure of arterial Oxygen }\end{array}$ & xygen & & \\
\hline
\end{tabular}

As PIM2 is calculated from the information collected at the time a child is admitted to the intensive care, PIM2 algorithm is calculation of PIM2 (and PIM2 risk of death\%) _ PIM2 val $=(0.01395 *$ (absolute $($ SBP-120) $))+(3.0791 *$ Pupils $)+(0.2888 *(100 *$ $\mathrm{FiO} 2 / \mathrm{PaO} 2))+(0.1040 *$ (absolute Base Excess $))+$ $(1.3352 *$ MechVent $)-(0.9282 *$ Elective $)-(1.0244 *$ Recovery $)+(0.7507 *$ Bypass $)+(1.6829 *$ HRdiag $)-$ (1.5770* LRdiag) -4.8841 . The PIM2 risk of death= exp PIM2 val/ (1+ expPIM2 val). For example, if a patient at the time of admission has a recorded systolic blood pressure of $55 \mathrm{mmHg}, \mathrm{PaO} 2$ of $110 \mathrm{mmHg}$, FiO2 0.5 , base excess -6.0 the pupils are reactive to light. Thus PIM2 val $=(0.01395 *$ [absolute $(55-$ $120))+(3.0791 * 0)+(0.2888 *(100 * 0.5 / 110))+(0.104$ * $|-6.0|)+(1.3352 * 1)-(0.9282 * 1)-(1.0244 *$ $1)+(0.7507 * 1)+(1.6829 * 1)-(1.5770 * 0)-4.8841$ $=-1.4059$. The probability of Death $=\exp (-1.4059) /[1$ $+\exp (-1.4059)]=0.1969$ or $19.7 \%$.

\section{Ethical consideration}

Regulate moral council Regard will a chance to be acquired former to endeavor those investigation.

Educated composed assent might have been got from guardian from claiming know taking an interest kids. 
No hazard for subjects who allotment in this contemplate.

Whatever unforeseen danger showed up Throughout the span of the examination might have been cleared with members and the moral council on time.

\section{3 Measurable dissection}

Those gathered information were tabulated Furthermore investigated utilizing SPSS rendition 16 product (SpssInc, Chicago, sick organization). Unmitigated information were exhibited Similarly as supreme What's more relative (\%) frequencies. Chisquare test (X2), alternately Fisher's accurate test (FET) were used to examine unmitigated variables. Learner " $t$ " test might have been used to examine regularly conveyed variables Around 2 free bunches. Same time non-parametric variables were broke down utilizing the mamoncillo Whitney what's to come for U test. Roc bend might have been used to focus those cutoff worth for ideal affectability Furthermore specificity. Relapse investigation might have been run should identify the predictors. Those acknowledged level from claiming essentialness in this fill in might have been expressed during $0.05(\mathrm{P}<0.05$ might have been viewed as significant).

\section{Comes about}

This table indicates that the intend of the agdistis (27. $20 \pm 28.646)$, and the rate of female $(50 \%)$, male $(50 \%)$ Table (1). This table reveals to that the rate of kicked the bucket (36\%), survive (64\%) Table (2). There were statistically critical build to PIM2 "around passed on over survive Table (3). There were statistically critical sure correlations between PIM2and (duration for sit tight (days), Fio2, Fio2 / pao2, hazard of mortality). There were no statistically huge correlations the middle of PIM2and other numerical information Table (4). This table indicates cut off purpose from claiming PIM2 score might have been $\geq-$ 2. 99 Furthermore auc might have been 0.79 ) Table (5) and Fig (1). No statistically noteworthy Contrast the middle of those watched and predicted mortality, with the goal PIM2 score could a chance to be utilized Similarly as an exact predictor about mortal sin for pediatric frigid. SMR equivalent watched mortal sin / normal mortal sin might have been $18 / 25=0.72$ i. $\mathrm{E}$ less person. It methods through estimation about mortal sin alternately useful execution of pediatric frigid. Predicted mortal sin might have been $50 \%$ Table( 6 ). There might have been statistically huge Contrast between passed on Also made due in regards to PIM score Table (7). There might have been statistically critical distinction the middle of passed on and made due viewing PIM score Table (8). This table show alignment of PIM2 score over four interim from claiming mortal sin hazard. The practically acknowledged system for measuring alignment is those goodness-of-fittest suggested Toward Hosmer and Leme hint at. The quality about $\mathrm{p}$ might have been required should make more excellent over 0.05 for great alignment of the model [8] Table (9).

Table (1) Demographic data of the studied sample.

\begin{tabular}{|c|c|c|c|}
\hline & Rang & Mean \pm SD \\
\hline \multirow{2}{*}{\multicolumn{2}{|c|}{ Age(months) }} & $1-120$ & $27.20 \pm 28.646$ \\
\hline & & No. & $\%$ \\
\hline & Female & 25 & 50.0 \\
\hline sex & Male & 25 & 50.0 \\
\hline
\end{tabular}

Table (2) Outcome of the studied sample.

\begin{tabular}{cccc}
\hline & & No. & \% \\
\hline \multirow{2}{*}{ outcome } & Died & 18 & 36.0 \\
& Survive & 32 & 64.0 \\
\hline
\end{tabular}

Table (3) Comparison between died and survive regarding PIM2 score.

\begin{tabular}{rrllll}
\hline & & Died & Survive & t.test & P.value \\
\hline PIM2 & Mean \pm & $6.19 \pm$ & $-4.67 \pm$ & 6.970 & .000 \\
& SD & 6.98 & 4.07 & & \\
\hline
\end{tabular}

Table (4) Correlation between PIM2 score and other variables.

\begin{tabular}{lcc}
\hline Correlation & \multicolumn{2}{c}{ Pearson's correlation } \\
\cline { 2 - 3 } & r & p \\
\hline Age(months) * PIM2 & $-.144-$ & 0.319 \\
HR * PIM2 & .126 & 0.383 \\
TM * PIM2 & $-.273-$ & 0.055 \\
SBP * PIM2 & $-.260-$ & 0.068 \\
DBP * PIM2 & $-.230-$ & 0.108 \\
duration of stay(days) * PIM2 & .373 & 0.008 \\
Fio2 * PIM2 & .401 & 0.004 \\
pao2 * PIM2 & $-.150-$ & 0.298 \\
Fio2 / pao2 * PIM2 & .385 & 0.006 \\
Base excee mmol/I * PIM2 & $-.025-$ & 0.861 \\
Risk of mortality * PIM2 & .794 & 0.000 \\
\hline
\end{tabular}


Table (5) Determination of cut off value of PIM2 score with highest sensitivity and specificity to predict death.

\begin{tabular}{lcccccccc}
\hline Cutoffpiont & Sens\% & Spec\% & PPV\% & NPV\% & Aacuracy\% & AUC & 95\% CI & P \\
\hline PIM2 & $94.4 \%$ & $75 \%$ & $68 \%$ & $96 \%$ & $82 \%$ & 0.79 & 0.67 to & $<0.001(\mathrm{H})$ \\
score $\geq$ & & & & & & & 0.91 & \\
-2.99 & & & & & & & & \\
\hline
\end{tabular}

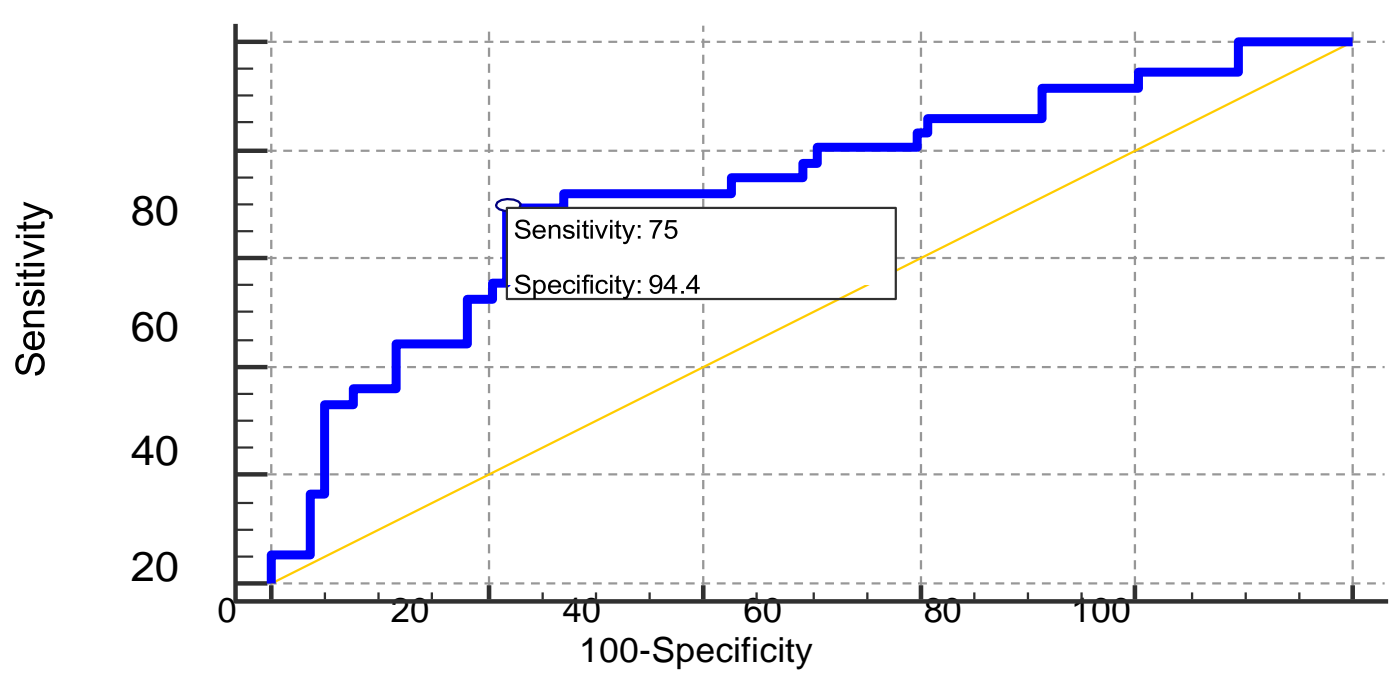

Fig (5) ROC curve for the validity and predictivityof PIM2 score in prediction of mortality

Table (6) Comparing observed and predicted mortality.

\begin{tabular}{|c|c|c|c|c|c|}
\hline & & & \multicolumn{2}{|c|}{ Observed mortality } & \multirow[t]{2}{*}{ Total } \\
\hline & & & Survived & Died & \\
\hline \multirow{9}{*}{$\begin{array}{l}\text { Predicted } \\
\text { Mortality }\end{array}$} & Survived & Count & 24 & 1 & 25 \\
\hline & & $\%$ within Predicted Mortality & $96.0 \%$ & $4.0 \%$ & $100.0 \%$ \\
\hline & & $\%$ within Observed mortality & $75.0 \%$ & $5.6 \%$ & $50.0 \%$ \\
\hline & Died & Count & 8 & 17 & 25 \\
\hline & & $\%$ within Predicted Mortality & $32.0 \%$ & $68.0 \%$ & $100.0 \%$ \\
\hline & & $\%$ within Observed mortality & $25.0 \%$ & $94.4 \%$ & $50.0 \%$ \\
\hline & & Count & 32 & 18 & 50 \\
\hline & & $\%$ within Predicted Mortality & $64.0 \%$ & $36.0 \%$ & $100.0 \%$ \\
\hline & & $\%$ within Observed mortality & $100.0 \%$ & $100.0 \%$ & $100.0 \%$ \\
\hline
\end{tabular}

McNemer's test was used

$\mathrm{P}=0.09(\mathrm{NS})$

Table (7) Observed mortality according to

\begin{tabular}{lccc}
\hline PIM score & Survived & Died & Total \\
\hline$>\mathbf{0}$ & 0 & 19 & $19(38 \%)$ \\
$\mathbf{0 t o - 2}$ & 0 & 4 & $4(8 \%)$ \\
$\mathbf{- 3 t o - 5}$ & 7 & 0 & $7(14 \%)$ \\
$<-5$ & 18 & 2 & $20(40 \%)$ \\
& 25 & $25(50 \%)$ & 50 \\
& $(50 \%)$ & & \\
\hline
\end{tabular}

$X^{2}=42.8 \quad P=0.000(H S)$
Table (8) Predicted mortality according to PIM2 PIM2score

\begin{tabular}{lccc}
\hline PIM score & Died & Survived & Total \\
\hline$>0$ & 16 & 3 & $19(38 \%)$ \\
Oto-2 & 0 & 4 & $4(8 \%)$ \\
-3 to-5 & 0 & 7 & $7(14 \%)$ \\
$<-5$ & 2 & 18 & $20(40 \%)$ \\
& 18 & 32 & 50 \\
& $(36 \%)$ & $(64 \%)$ & \\
\multicolumn{2}{c}{$\mathrm{P}=0.000(\mathrm{HS})$} & & \multicolumn{2}{c}{$\mathrm{X}^{2}=31.2$}
\end{tabular}


Table (9) Calibration of PIM2 score.

\begin{tabular}{|c|c|c|c|c|c|c|}
\hline $\begin{array}{l}\text { PIM } \\
\text { score }\end{array}$ & $\begin{array}{c}\text { Observed } \\
\text { death }\end{array}$ & $\begin{array}{l}\text { Expected } \\
\text { death }\end{array}$ & $\mathbf{P}$ & $\begin{array}{c}\text { Observed } \\
\text { srvival }\end{array}$ & $\begin{array}{c}\text { Expected } \\
\text { survival }\end{array}$ & $\mathbf{P}$ \\
\hline$>0$ & 16 & 19 & $>.05$ & 3 & 0 & \\
\hline 0to-2 & 0 & 4 & (NS) & 4 & 0 & $>.05$ \\
\hline-3 to-5 & 0 & 0 & & 7 & 7 & (NS) \\
\hline \multirow[t]{2}{*}{$<-5$} & 2 & 2 & & 18 & 18 & \\
\hline & 18 & 25 & & 32 & 25 & \\
\hline
\end{tabular}

\section{Discussion}

Our investigation might have been directed once fifty critically sick patients agdistis more than 1 month and less 16 a considerable length of time. In the current study we found that sex might have been rise to "around the examined situations. This is for understanding with those consider carried by [9]who settled on prospective examine which might have been led in the beijing Chao-yang healing center. They discovered that sex might have been equivalent Around the admitted pediatric cases.

This ponder indicated that, viewing period extending from 1 will 120 months with mean period 27. 2 months of age. This agrees with [10]who recognized that know youngsters more youthful over 5 a considerable length of time of age were those powerless age class speaking to those greater part for admitted patients with PICU.

In the exhibit study, viewing result of the examine number demise rate might have been (36\%). This is in understanding [10] who found mortality might have been $33.1 \%$. Also, $44.5 \%$ in the [12] study.

Opposite should our results, [13] reported a low mortal sin from claiming 2. 6\%. They offered illustration to this Similarly as sepsis might have been essentially underrepresented "around their ponder populace $(2.3 \%)$.

This contemplate indicated that, pediatric list of mortal sin 2 (PIM 2) score were fundamentally higher "around demise over released situations $(\mathrm{P}<0.05)$. This agrees [2] who found that, pediatric list about mortal $\sin 2$ ( PIM 2) score were altogether higher Around demise over made due instances $(\mathrm{P}<0.05)$. This may be in understanding also for [4] who discovered that, pediatric list of mortal sin 2 ( PIM 2) score were essentially higher "around demise over made due situations $(\mathrm{P}<0.05)$.

Over our study, measurable critical certain correspondence between PIM2 score What's more (risk about mortal sin Also span for stay). This will be in understanding for [14]who found that, Factual noteworthy sure connection between PIM2 score What's more (risk for mortal sin What's more span about stay).

With accept At whatever mortal sin score system, 3 focuses must be discussed; the institutionalized mortal sin proportion (SMR), separation and alignment.
The mortal sin might have been institutionalized for body of evidence blend utilizing those institutionalized mortal sin proportion. Those SMR is computed Toward isolating those real mortality Eventually Tom's perusing the predicted mortality of the study number. Assuming that SMR less 1, it intends an overestimation of mortal sin in the PICU Toward the score or finer execution Toward those PICU contrasted with the PICUs that produced the scoring framework. If SMR more than 1, the opposite may be valid.

Clinched alongside our study, the genuine mortality might have been $36 \%$ and the predicted mortality Toward PIM 2 score might have been 50\%, Along these lines the institutionalized mortal sin proportion might have been 0.72 signifying overestimation of mortality or beneficial execution from claiming our unit. This is in understanding with a few writers [15]found that the institutionalized mortal sin proportion about PIM 2 might have been 0.86 .

Done japanese PICU, [16]found that those institutionalized mortal sin might have been 0.77 . On argentina [17]found that those institutionalized mortal sin proportion for PIM 2 might have been 0.85 .

[8]found that SMR to PIM 2 might have been 1.4 which is as opposed with our consequence.

Done Iran, An prospective companion consider on accept PIM2 execution Previously, a tertiary doctor's facility over Tehran, the watched mortalities Around know youngsters admitted of the PICU arrived at $15 \%$, same time PIM2 predicted mortal sin might have been 8. $3 \%$, SMR is 1.8 (95\% ci 1. 28-2. 46). [18]. Separation may be the capacity of a test on figure a higher mortal sin likelihood "around non-survivors over survivors over those entirety aggregation. Over different words, separation may be critical same time recognizing those result Possibly survival alternately moribed "around those admitted patients [8].

Mortal sin separation might have been quantified Toward figuring those zone under the roc bend ( a plot about sensitivety versus 1 - specificity). Those zone under those roc bend (AUC) gives An parameter for biased execution of the model. A territory for $<0.5 \rightarrow$ bad, a territory for $0.5-0.69 \rightarrow$ fair, a territory about 0 . $7-0$. $8 \rightarrow$ good, a territory for $0.8-0.9 \rightarrow$ thick, as handy. Auc $>0.9 \rightarrow$ fantastic.

The introduce ponder shows also a great biased capability from claiming PIM2 with separate survivors starting with non-survivors (AUC $0.79,95 \%$ ci 0.67 with 0.91). 
Done al Fayoum school [19]found that auc to PIM might have been 0.75 . [11] showed that PIM2 score needed handy separation with range under roc constantly 0.82 (95\% CI: $0.72-0.92)$ clinched alongside An PICU of a Creating particular nation.

This perception is in understanding for a significant number investigations. A prospective examine clinched alongside five PICU settings in the uk archived a great separation for PIM2 model (AUC 0. 84, 95\% ci 0.819 on 0. 853). [20]. In Japan, PIM2 demonstrated fantastic separation done a prospective companion investigation including 2536 kids admitted of the biggest PICU, the place the auc worth might have been 0.92 (95\% ci 0 . 89-0. 96). [11]. In India, PIM2 discriminated great the middle of survivors Furthermore non-survivors admitted on An tertiary healing center done india with auc 0. 843 (95\% ci 0. 76-0. 90). [14]. Alignment measures the correspondence between the predicted results What's more real result In those whole extent from claiming danger prediction. On other words, alignment will be a greater amount critical same time comparing anticipated What's more watched result toward Different intervals of seriousness. Those The greater part acknowledged technique to measuring alignment may be the goodness-of-fit test. The quality about $\mathrm{p}$ might have been needed should be more terrific over 0.05 for great alignment of the model [8].

Clinched alongside our study, PIM2 hint at great alignment ( $\mathrm{p}>0.05$ Previously, nonsurvivors Furthermore done survivors).

This will be in understanding with other investigations demonstrated finer calibration; [8]reported same discoveries ( $\mathrm{p}=0.32$ What's more $\mathrm{p}=0$. 29, respictively). An investigation from italy connected PIM2 Furthermore discovered that it align great $(\mathrm{p}=0.26)$ carried by [21].

Anyhow On italy by [22]Calibration might have been lesquerella satisfactory, $(p<0.001)$.

\section{Conclusion}

In our study, the actual mortality rate was $36 \%$ and the predicted mortality rate by PIM 2 score was $50 \%$, so the standardized mortality ratio was 0.72 signifying overestimation of mortality rate and/or good performance of our unit. The present study demonstrates a good discriminatory ability of PIM2 to differentiate survivors from non-survivors (AUC 0.79, 95\% CI 0.67 to 0.91 ). In our study, PIM2 show well calibration $(\mathrm{p}>0.05$ in nonsurvivors and in survivors).PIM2 is easily calculated and is freely available, thus provides a good incentive for ICU settings in Egypt for admission of high risk patients. PIM2 provides a consistent guide to the performance of our PICU.

\section{References}

[1] P.Tyagi, M. Agrawal, M.Tullu, Comparison of Pediatric Risk of Mortality III, Pediatric Index of Mortality 2, and Pediatric Index of Mortality 3 in
Predicting Mortality in a Pediatric Intensive Care Unit. Journal of Pediatric Intensive Care, Vol. 7(4), PP.201-206, 2018.

[2] M.R. Labib Youssef, H. Mosleh , J.Rene Labib ,Assessment of the performance of the Pediatric Index of Mortality 2 (PIM2) among Egyptian pediatric patients admitted to the intensive care. Egypt PediatrAssocGaz;Vol. 62,PP.65-71,2014.

[3] A .Khajeh, N.M. Noori , M.Reisi Mortality risk prediction by application of pediatric risk of mortality scoring system in pediatric intensive care unit. Iran J Pediatr, Vol. 23, PP.546-550, 2013.

[4] R.A. Yousef, F.M. El Gendy , A.A.Abd El Aziz , Prognostic scoring systems in pediatric ICUs: Pediatric Risk of Mortality III versus Pediatric Index of Mortality 2. Alex J Pediatr;Vol.32,PP.27$32,2019$.

[5] A .Abdelkader, M.M. Shaaban , M.Zahran, Using two scores for the prediction of mortality in pediatric intensive care units. Al-AzharAssiut Med J, Vol.16, PP.349-55, 2018.

[6] J.Ramazani, M.Hosseini , Prediction of ICU mortality in critically ill children. Med KlinIntensivmedNotfmed ;Vol.63,PP.18-484,,2018.

[7] A. Slater, F .Shann, G.Pearson , PIM2: a revised version of the paediatric index of mortality. Intensive Care Med;Vol.29,PP.278-85,2003.

[8] A.U.Qureshi, A. S. Ali , T.M. Ahmad ,Comparison of three prognostic scores (PRISM, PELOD and PIM2 )at pediatric intensive care unit under Pakistani circumstances .J Ayub Med Coll Abbottabad, Vol.19 (2) ,PP.49 -53,2007.

[9] B. Liu, Y .Chen, Q. Yin, Diagnostic value and Prognostic evaluation of presepsin for sepsis in an emergency department. Critical care; Vol. 17,PP.R244,2013.

[10] H.I. Rady , N.A. Mohssen, Application of different scoring systemsand their value in pediatric intensive care unit. Gaz Egypt PediatrAssoc, Vol. 62, PP.59-64, 2014.

[11] S. Hariharan, K. Krishnamurthy , D. Grannum , Validation of Pediatric Index of Mortality-2 scoring system in a Pediatric Intensive Care Unit, Barbados. J Trop Pediatr, Vol.57(1), PP.9-13, 2011.

[12] B. Khwannimit, R. Bhurayanontachai , V .Vattanavanit, Comparison of the performance of SOFA, qSOFA and SIRS for predicting mortality and organ failure among sepsis patients admitted to the intensive care unit in a middle-income country. J Crit Care ;Vol.44,PP.156-160,2018.

[13] K.M. Choi, S.F. Wong, Assessment of the Pediatric Index of Mortality (PIM) and the Pediatric Risk of Mortality (PRISMIII) score for the prediction of mortality in apediatric intensive care unit in Hong Kong.Hong Kong Med, Vol.11, PP.97-113, 2005.

[14] J.Gandhi, S.Sangareddi, P.Varadarajan, Pediatric index of mortality 2 score as an outcome predictor in pediatric Intensive Care Unit in India. Indian journal of critical care medicine : peer-reviewed, 
official publication of Indian Society of Critical Care Medicine, Vol. 17(5), PP.288-291,2013.

[15] S. Hariharan, L. Merritt-Charles, D. Chen ,Riskadjusted out come evaluation in a multi disciplinary intensive care unit. West Indian Med J, Vol.56(3), PP.240-5, 2007.

[16] T .Imamura , S .Nakagawa , R .D. Goldman , Validation of pediatric index of mortality 2 (PIM2) in asingle pediatric intensive care unit in Japan .Intensive Care Med, Vol.38(4), PP.649-54,2012.

[17] P .G. Eulmesekian, A. Perez, P. G. Minces ,Validation of pediatric index of mortality 2 (PIM2) in asingle pediatric intensive care unit of Argentina. Pediatr Crit Care Med, Vol.8, PP.54-7, 2007.

[18] P. Salamati, S .Talaee, A .Eghbalkhah, Validation of pediatric index of mortality-2 scoring system in a single pediatric intensive care unit in Iran. Iran $\mathbf{J}$ Pediatr, Vol.22(4), PP.481-6, 2012.

[19] O.Bekhit, A. A.Algameel, H. H. Eldash,
Application of pediatric index of mortality version 2: score in pediatric intensive care unit in an African developing country. The Pan African medical journal, Vol. 17, PP.185-10, 2014.

[20] G. A. Pearson , E. Stickley Jand Shann, Calibration of the pediatric index of mortality in UK pediatric intensive care units . Arch Dis Child, Vol.84, PP.125-8, 2001.

[21] A. Wolfler, P. Silvani, M. Musicco, Italian Pediatric Sepsis Study (SISPe) Group. Pediatric Index of Mortality 2 score in Italy : amulti center ,prospective ,observational study. Intensive Care Med, Vol.33(8), PP.1407-13, 2007.

[22] M.L.C. Atti, M. Cuttini, L. Rava , Performance of the pediatric index of mortality 2 (PIM-2) in cardiac and mixed intensive care units in atertiary children's referral hospital in Italy. BMC pediatr, Vol.13, PP.100, 2013. 